\title{
PAMA implementation: The road ahead
}

\author{
Rami Doukky, MD, MSc, FASNC ${ }^{\mathrm{a}, \mathrm{b}}$ \\ a Division of Cardiology, Cook County Health, Chicago, IL \\ b Division of Cardiology, Rush University Medical Center, Chicago, IL
}

Received Oct 21, 2019; accepted Oct 21, 2019

doi: $10.1007 / \mathrm{s} 12350-019-01942-2$

As of January 1, 2020, the Centers for Medicare and Medicaid Services (CMS) has implemented \$218(b) of the Protecting Access to Medicare Act (PAMA) of 2014. The law was enacted by Congress to minimize the use of rarely appropriate advanced diagnostic imaging studies (radionuclide imaging, magnetic resonance imaging, and computed tomography) provided to Medicare beneficiaries. ${ }^{1}$ Under this program, at the time a practitioner orders an advanced diagnostic imaging study for a Medicare beneficiary, he/she will be required to consult a qualified Clinical Decision Support Mechanism (CDSM). CDSMs are electronic portals through which appropriate use criteria (AUC) are accessed. The CDSM provides a determination of whether the order adheres to AUC, or if the clinical scenario was not addressed by AUC. A consultation must take place at the time of the order for imaging services to be paid by Medicare. Ultimately, practitioners whose ordering patterns are considered "outliers" will be subject to prior authorization. Definition of "outliers" and methodology of prior authorization have not yet been established. This program impacts all practitioners who order advanced diagnostic imaging studies, regardless of specialty, as well as physicians and facilities that furnish advanced diagnostic imaging services in any setting, whether their claims are paid under the physician fee schedule or Hospital Outpatient Prospective Payment System (HOPPS). ${ }^{1}$ Since July 1, 2018, this program has been operating under a voluntary participation period. As of January 1, 2020, the program has entered an "Education and Operations Testing Period," during which claims will not be denied for failing to include proper AUC consultation information. The program is set to be fully implemented on January 1, 2021, which means AUC

Reprint requests: Rami Doukky, MD, MSc, FASNC, Division of Cardiology, Cook County Health, 1901 W. Harrison St., Chicago, IL 60612, USA; rami_doukky@rush.edu

J Nucl Cardiol 2019;26:1789-91.

$1071-3581 / \$ 34.00$

Copyright (C) 2019 American Society of Nuclear Cardiology. consultations using qualified CDSMs are required, along with reporting of this information on the professional and technical claims for the advanced diagnostic imaging service. Claims that fail to comply will not be paid. CMS finalized 8 "Priority Clinical Areas" which will be used to benchmark providers according to their utilization of rarely appropriate imaging studies. ${ }^{1}$ Since known or suspected coronary artery disease evaluation is a priority clinical area, the vast majority of cardiac imaging studies will be subject to the initial roll-out of the AUC mandate. Furthermore, CMS has identified qualified "Provider Led Entities"' (professional organizations) which have developed or endorsed applicable AUC. ${ }^{1}$ The AUC developed by the American College of Cardiology (ACC), the American Society of Nuclear Cardiology (ASNC), and many other professional societies are among those approved by CMS. ${ }^{2}$ As a result of PAMA implementation, there will be a massive shift wherein the burden of reducing inappropriate use will move largely from payers to providers. Most physicians are unprepared for this paradigm shift.

ASNC and its membership pioneered the AUC movement along with the ACC. ${ }^{2,3}$ Many investigators from ASNC membership have reported on adherence and determinants of AUC use and the impact of AUC on patient outcomes, radiation exposure, and cost effectiveness. $^{4-12}$ Furthermore, cardiovascular specialists demonstrated the value of systematic implementation of CDSM to minimize the utilization of rarely appropriate cardiac imaging studies and maximize the use of appropriate medical therapy. ${ }^{13}$ Much of this literature was, in fact, published in this very journal. Moreover, adherence to AUC in common clinical scenarios are key performance measures in the ASNC ImageGuide ${ }^{\mathrm{TM}}$ registry. ${ }^{14,15}$ ASNC has engaged a number of non-cardiology organizations to promote appropriate use in clinical practice. ${ }^{16}$ Despite ASNC's unwavering commitment to AUC, there are a lot of uncertainty and concerns surrounding the use of PAMA as a hammer tool to force the implementation of AUC. 
It has been clear since the inception of PAMA that the implementation of the AUC mandate is fraught with problems, not only for clinicians, practices, and imaging facilities, but also for CMS. There are many indications suggesting that this program is challenging to implement. In fact, the repeated delays in the program's implementation (2017 to 2018, and then 2020) are a clear manifestation of these challenges. The program provides no flexibility in the way clinicians can consult AUC. The law establishes a complex exchange of information between ordering and furnishing clinicians or facilities and rigorous documentation on Medicare claim forms. These complexities forecast a number of clinical, technical, and operational challenges.

One of the more difficult clinical transitions will be situations that require physicians to switch the AUC they consult. Many institutions have acquired CDSM that do not include the AUC developed by the cardiovascular societies. Thus, cardiologists who have more than 10 years of experience using the AUC promulgated by ACC/ASNC and other cardiovascular societies now find themselves having to use AUC developed by other provider-led entities, such as the American College of Radiology (ACR). It has been shown that there are substantial discordances in appropriateness determination between AUC developed by ACC vs ACR. ${ }^{17}$ For example, there are many clinical scenarios addressed by the AUC developed by ACC that could not be matched to any scenario outlined by ACR, or where the AUC determinations were at odds. These discordances may translate into differences in clinically relevant outcomes, such as the detection of myocardial ischemia. ${ }^{17}$ How conflicts between AUC developed by various physicianled entities will ultimately affect the identification of outliers is unknown.

Another implementation difficulty stems from the fact that the program applicability is vast, affecting any clinician who orders and/or furnishes an advanced diagnostic imaging test. Thus, a tremendous amount of provider education for the AUC program will be required, but not provided in the mandate. Unfortunately, despite best efforts of many organizations, a substantial proportion of practicing physicians are unaware of the program and how it will impact their practice.

Furthermore, the communication and documentation of CDSM determination are likely to cause significant operational problems. Information stemming from CDSM, such as AUC determination and confirmation codes, needs to be communicated between the ordering physician and furnishing clinician or entity in order for the test to be performed and paid for by CMS. This flow of information can be easily overcome in an integrated health system, but for those physicians in separate private practices, this transaction will likely be a challenge.

Many other questions arise around the AUC mandate. How will CMS define "outlier" physicians, particularly when applying different AUC with disparate rigor in determining appropriateness? What will be the impact of PAMA on small practices that may not be able to implement CDSM? Will primary care physicians order more consults or a "wrong" test, just to circumvent an encounter with CDSM, thereby driving up costs? Will providers input inaccurate clinical information in order to overcome a stringent CDSM tool? Most importantly, how will the AUC mandate impact patients' access to testing, experience, and outcomes?

Despite these concerns, PAMA is here, so what is the outlook of the road ahead? For the past 3 years, ASNC has been busy trying to cushion the potential negative impact of the AUC mandate on its members and practicing physicians. The AUC steering committee, launched by ASNC in 2016, has initiated dialogue with other professional societies, including the American College of Physicians, in an effort to educate the referring physicians about the value of AUC and the importance of selecting the right test, for the right patient, at the right time. Many teaching cases and scholarly communications have been developed for this purpose. Broader collaboration between organizations representing referring providers and imaging specialists is a critical step to raising awareness of expectations under PAMA. Furthermore, grassroots efforts should focus on demanding expanded access to AUC developed by ACC/ASNC and other cardiovascular societies into commercially available CDSM products. Seamless integration of CDSMs in the electronic order entry systems to provide real-time guidance with minimal provider burden is a crucial area for progress. Although CDSMs can aid in improving utilization, optimal success is achieved by understanding the potential value (or lack thereof) of each and every imaging test; thus, it is critical to continue relentless educational initiatives targeting referring physicians of all specialties as well as advanced practice providers. Finally, ASNC, professional societies, providers, imaging facilities, and health systems should take advantage of the "Education and Operations Testing Period" in 2020 to monitor for aforementioned potential unintended consequences of implementing the AUC mandate, particularly patient access to testing, delay in care, unnecessary consultation, and inadequate alternative testing. Indeed, it does take considerable sustained efforts to move us towards appropriate and sensible utilization of healthcare resources. Critical to the success of any such effort is involvement of all stakeholders from imaging specialists to primary care providers, training programs, payers, 
health systems, and patients to fully realize the benefits of AUC and extend them to other areas of medicine.

\section{Acknowledgments}

The author would like to thank Georgia Hearn, JD and the members of ASNC AUC Steering Committee for their insights.

\section{Conflicts of interest}

The author has received research grant funding from Astellas Pharma Global Development (Northbrook, IL).

\section{References}

1. Centers for Medicare \& Medicaid Services. Appropriate Use Criteria Program. CMS.gov. https://www.cms.gov/Medicare/Qua lity-Initiatives-Patient-Assessment-Instruments/Appropriate-UseCriteria-Program/index.html. Accessed 21 Oct 2019.

2. Wolk MJ, Bailey SR, Doherty JU, Douglas PS, Hendel RC, Kramer CM, et al. ACCF/AHA/ASE/ASNC/HFSA/HRS/SCAI/ SCCT/SCMR/STS 2013 multimodality appropriate use criteria for the detection and risk assessment of stable ischemic heart disease: A report of the American College of Cardiology Foundation Appropriate Use Criteria Task Force, American Heart Association, American Society of Echocardiography, American Society of Nuclear Cardiology, Heart Failure Society of America, Heart Rhythm Society, Society for Cardiovascular Angiography and Interventions, Society of Cardiovascular Computed Tomography, Society for Cardiovascular Magnetic Resonance, and Society of Thoracic Surgeons. J Am Coll Cardiol. 2014;63:380-406.

3. Brindis RG, Douglas PS, Hendel RC, Peterson ED, Wolk MJ, Allen JM, et al. ACCF/ASNC appropriateness criteria for singlephoton emission computed tomography myocardial perfusion imaging (SPECT MPI): A report of the American College of Cardiology Foundation Quality Strategic Directions Committee Appropriateness Criteria Working Group and the American Society of Nuclear Cardiology endorsed by the American Heart Association. J Am Coll Cardiol. 2005;46:1587-605.

4. Doukky R, Hayes K, Frogge N. Are cardiologists truly better at appropriately selecting patients for stress myocardial perfusion imaging? Int J Cardiol. 2014;176:285-6.

5. Doukky R, Hayes K, Frogge N, Nazir NT, Collado FM, Williams KA. Impact of insurance carrier, prior authorization, and socioeconomic status on appropriate use of SPECT myocardial perfusion imaging in private community-based office practice. Clin Cardiol. 2015;38:267-73.

6. Doukky R, Frogge N, Appis A, Hayes K, Khoudary G, Fogg L, et al. Impact of appropriate use on the estimated radiation risk to men and women undergoing radionuclide myocardial perfusion imaging. J Nucl Med. 2016;57:1251-7.

7. Doukky R, Hayes K, Frogge N. Appropriate use criteria for SPECT myocardial perfusion imaging: Are they appropriate for women? J Nucl Cardiol. 2016;23:695-705.

8. Doukky R, Hayes K, Frogge N, Balakrishnan G, Dontaraju VS, Rangel MO, et al. Impact of appropriate use on the prognostic value of single-photon emission computed tomography myocardial perfusion imaging. Circulation. 2013;128:1634-43.

9. Elgendy IY, Mahmoud A, Shuster JJ, Doukky R, Winchester DE. Outcomes after inappropriate nuclear myocardial perfusion imaging: A meta-analysis. J Nucl Cardiol. 2016;23:680-9.

10. Hayes-Brown K, Frogge N, Doukky R. The impact of appropriate use on the cost effectiveness of SPECT myocardial perfusion imaging in the community setting. J Am Coll Cardiol. 2014;63(12 Supplement):A1222.

11. Malhotra S, Doukky R. Differential impact of appropriate use criteria on the association between age and an abnormal stress myocardial perfusion SPECT. Cardiovasc Innov Appl. 2019;4:639.

12. Hendel RC. The value and appropriateness of positron emission tomography: An evolving tale. J Nucl Cardiol. 2014;22(1):16-21.

13. Lin FY, Dunning AM, Narula J, Shaw LJ, Gransar H, Berman DS, et al. Impact of an automated multimodality point-of-order decision support tool on rates of appropriate testing and clinical decision making for individuals with suspected coronary artery disease: A prospective multicenter study. J Am Coll Cardiol. 2013;62:308-16.

14. Tilkemeier PL, Bourque J, Doukky R, Sanghani R, Weinberg RL. ASNC imaging guidelines for nuclear cardiology procedures: Standardized reporting of nuclear cardiology procedures. J Nucl Cardiol. 2017;24:2064-128.

15. Tilkemeier PL, Doukky R, Kirkpatrick JN, Desai MY, Nagueh SF. Coming-of-age: The ImageGuide Registry at three. J Nucl Cardiol. 2018. https://doi.org/10.1007/s12350-018-1442-1.

16. Doukky R, Diemer G, Medina A, Winchester DE, Murthy VL, Phillips LM, et al. Promoting appropriate use of cardiac imaging: No longer an academic exercise. Ann Intern Med. 2017;166(6):438-40.

17. Winchester DE, Wolinsky D, Beyth RJ, Shaw LJ. Discordance between appropriate use criteria for nuclear myocardial perfusion imaging from different specialty societies: A potential concern for health policy. JAMA Cardiol. 2016;1:207-10.

Publisher's Note Springer Nature remains neutral with regard to jurisdictional claims in published maps and institutional affiliations. 